\title{
Palavra de Mulher: sobre a "voz das mulheres" e a história grega antiga
}

\author{
A Woman's Speech: "Women's Voice" \\ and the Ancient Greek History
}

Marta Mega de Andrade*

\section{Resumo}

O artigo discute o logos gunaikos, "palavra de mulher", como problemática nos estudos de história antiga grega. Assumindo essa questão como contemporânea, evoca a possibilidade de construir conhecimento histórico sobre a palavra e a ação política das mulheres na pólis, com base em leituras de tragédias e comédias gregas bem como dos epigramas funerários dedicados às mulheres e característicos do final do século $\mathrm{V}$ e início do século IV a.C. em Atenas. Explora a dimensão do cotidiano como espaço/tempo de uma política constituinte não necessariamente centrada nos espaços institucionais de decisão e governo. Afirma ser possível perceber nessas fontes a persistência de requisições femininas aquém do direito políade, validadas pela comunidade e pela dimensão da "vida comum", mesmo que as "vozes" não sejam passíveis de identificação a uma autoria feminina. Palavras-chave: política; cotidiano; comunidade; mulheres; Atenas clássica.

\section{Abstract}

This article discusses the gunaikos logos, "woman's speech", as a problem in studies of ancient Greek history. Assuming the issue as a contemporary issue, it evokes the possibility of building historical knowledge about the political word and action of women in the polis, from readings of Greek tragedy and comedy as well as funerary epigrams dedicated to women and characteristics of the end of the 5th and early 4 th century BC in Athens. It explores the dimension of everyday life as space/time of a constituent politics not necessarily centered on institutional spaces for deliberation and government. It claims that it is possible to perceive through these sources the persistence of female requests that fall short of the political right, validated by the community and the dimension of "common life", even if the "voices" are not amenable to identification by a female authorship.

Keywords: politics; everyday life; community; women; classical Athens.

\footnotetext{
* Universidade Federal do Rio de Janeiro (UFRJ), Rio de Janeiro, RJ, Brasil. martamega@gmail.com $<$ https://orcid.org/0000-0002-6437-0479>
} 
Podem certas vozes ser ouvidas quando delas nada foi "gravado"? Podemos falar por elas com as premissas do presente? Temos o direito de subentender, conjecturar, preencher lacunas com tekméria, aqueles indícios tão caros à "prova" sobre os quais nos fala Ginzburg em Relações de força (Ginzburg, 2002, p. 13-63)? Podemos intuir, pressentir, podemos nos aproximar com empatia? Tais questionamentos nos parecem tão deslocados do ponto de vista da História definida como análise crítica de fatos ou feitos que imprimiram uma marca qualquer na memória de cronistas e documentos institucionalizados, autorais, datáveis... e constituem, contudo, questionamentos importantes para aqueles dentre os historiadores que escolheram lidar com os "sem história" na História. Acredito que já tenhamos ultrapassado a fase preliminar da problemática colocada nos anos 1980 pela história das mulheres na Antiguidade grega, sobre a inexistência ou impossibilidade de se conferir a essas mulheres - ou, no que interessa a este artigo, às mulheres de Atenas - autoralidade e, por conseguinte, voz própria. Deixando de lado a crítica que pode ser feita a essa percepção de uma relação entre "autoralidade" e "propriedade" da voz, nosso momento, hoje, é o de uma busca por pluralização das vozes, uma busca pela diferença e pela alteridade que nos ensine mais sobre nós mesmos. E, nesse caso, a pluralidade e a descentralização só podem advir de uma desconstrução das fontes, uma espécie de "despensamento" das fontes textuais. Já escrevemos muito sobre os vieses dos autores no que se refere às formas de recepção, enfim, sobre os textos que continuam a representar a maior parte dos corpora das pesquisas. O que falta ao estudo das mulheres nas fontes textuais atenienses, na medida em que "mulheres" geralmente não são o "tema" de uma compreensão mais ampla da maioria dessas fontes, é uma atenção ao detalhe, ao pequeno, ao menor.

No presente artigo, apresento algumas discussões nesse sentido, calcadas em exercícios de leitura de tragédias, comédias, orações áticas e epigramas funerários. $\mathrm{O}$ artigo representa uma enquete que está muito longe de seu fim e cujas conclusões apontam possibilidades e não teses. Na primeira parte - a cidade das mulheres - discuto o protagonismo feminino com base no estudo de caso de alguns contextos de exposição pública de figuras femininas. $\mathrm{Na}$ segunda parte - confesso aqui a inspiração em Detienne (1988) e Vernant (2002) - busco nesses contextos de exposição pública a "palavra" atribuída às mulheres, assumindo, como parte da hipótese, que essa palavra, exposta, e ao mesmo tempo cotidiana (pertencente ao âmbito da vida comum), é uma palavra política mesmo quando a ela se atribui vanidade. Experimento, nesse 
caso, as noções de "espaços livres", "heterotopias" e "política constituinte", cujos desdobramentos exploro nas considerações finais.

\section{A CIDADE DAS MULHERES}

Havia uma cidade no centro do imaginário da origem da civilização ocidental europeia e branca, e essa cidade era Atenas. Muito girava em torno do modelo ateniense: democracia, pensamento, política, o exemplo de suas mulheres... Mas essa história não começa lá, em um ano qualquer e - diga-se de passagem - inexistente na notação do tempo deles. Essa história começa aqui e é sobre a Atenas clássica. Ela começa entre nós, no classicismo do século XIX, e no espelhamento das diferenças que tomou conta da historiografia no pós-Segunda Guerra Mundial. ${ }^{1}$ Assim, por exemplo, nos idos de 1976 Augusto Boal adaptou a peça Lisístrata para o teatro sob o título Lisa, a libertadora. Embora a peça não tenha sido encenada, a canção Mulheres de Atenas, escrita para ela, fez tanto sucesso que ecoou por décadas na memória coletiva, pois ao mesmo tempo resumia toda a imagem que tínhamos das mulheres atenienses e atingia o coração do ativismo feminista em tempos de cólera, com seu olhar irônico e crítico. Em contexto, isto é, reinserida na leitura que Boal e Chico Buarque fizeram da comédia grega, mirar-se no exemplo das mulheres de Atenas não apenas revela ao oprimido as condições da opressão, mas também confere a ele o exemplo literal de uma luta. As mulheres de Atenas vivem para seus maridos que são o orgulho e raça de Atenas, como dizem as orações fúnebres aos mortos em guerra na Atenas clássica; mas também, como diz em monólogo Medeia, a protagonista da peça de Eurípides. A formação do dramaturgo Boal e do compositor Chico Buarque fora suficientemente clássica para que eles soubessem exatamente do que estavam falando em 1976: o limiar entre viver subordinado e agir, mudar a história, acabar com a guerra, negar à cidade o nascimento de varões. Retirada desse contexto em que um tempo constrói obras com outro tempo, contexto desta leitura que envolve o cruzamento de uma cultura clássica recebida com os dilemas intensamente vividos na contemporaneidade dos autores, a canção de Chico Buarque pareceria (e pareceu) um hino à queima dos sutiãs quando, no entanto, sua força vai muito além. Ela diz respeito à subalternidade em história e à reivindicação de outra história para a qual a "voz das mulheres" é pedra fundamental.

Em 1976, o contraponto entre a vida doméstica de uma esposa e a vida pública - universidade, mundos do trabalho e da opinião, resistência política - reivindicada pela e para a liberdade das mulheres já havia penetrado no meio 
acadêmico da produção de conhecimentos que englobarei aqui sob a rubrica do women studies norte-americano. A história das mulheres, história de um grupo social definido pelo gênero, classe, raça, tentava se firmar nesse campo dominado pela história universal de parâmetros iluministas. Primeiramente, "a mulher" na história; em seguida, "as mulheres". A necessidade de encontrá-las, resgatá-las, conferir visibilidade a suas ações, fez proliferar os estudos: criou-se uma heterotopia. ${ }^{2} \mathrm{O}$ que Joan Scott chama de "lógica do suplemento" (Scott, 1992, p. 75-77), algo que vem para complementar, mas que ao mesmo tempo descobre-se deslocado, sem encaixe possível. Deslocamento de lugar, de tempo, de natureza, de discurso, de valor... As mulheres (ocidentais) não "cabiam" na história dos homens (ocidentais), de modo que enunciados como "mulheres na corte do primeiro reinado" poderiam prometer narrativas mantendo intactos os protagonismos.

Isso mostra como a questão do protagonismo é central para a elaboração de uma narrativa histórica possível sobre uma Atenas das mulheres. Já sabíamos desde Cohen (1989) e Sourvinou-Inwood (1995a) que as mulheres a quem os atenienses denominavam astai, "cidadãs", tinham papel importante constantemente reiterado, aliás, pelos ideais normativos que impunham seus lugares a homens e mulheres (não necessariamente cidadãos), tanto na gestão cooperativa da casa quanto no domínio da condução de práticas e ritos religiosos. Costumamos menosprezar como historicamente questionável esse lugar comum da gestão da casa e da religião, por motivos diferentes. Primeiro, por tratar-se de uma sociedade patriarcal e patrimonial, a noção de gestão cooperativa presente no Econômico, de Xenofonte (VII, 18-22), perde seu sentido preciso para constituir corolário de uma ideologia de (dominação de) gênero (Pomeroy, 1994). Independentemente de se perguntar se as mulheres esposas tinham tal prerrogativa ou não na gestão de um oikos em que elas entravam como estranhas, devemos enfatizar que a proposta de complementaridade no casamento oferece, de fato, um lugar que pode ser reivindicado por aquelas que adquirem tal condição (esposas de cidadãos com posses, modelo feminino de status mais elevado). ${ }^{3}$

Em segundo lugar, a dimensão religiosa das práticas sociais na sociedade políade é pouco estudada quando se toma como referência o locus da agência política. Historiograficamente, como já discutimos anteriormente, concentram-se na forma da cidade-Estado os problemas, objetos e temas da história política. ${ }^{4} \mathrm{E}$ com essa atitude privamo-nos de abordar justamente aquela esfera pública comum e muito mais abrangente do que as instituições políticas, onde diversas questões, inclusive políticas, econômicas e jurídicas, eram formuladas 
e encontravam ressonância no âmago das relações "costumeiras" (Mansouri, 2002; Guarinello, 2003; Vlassopoulos, 2007; Soares, 2014; Harris, 2016). Sobretudo, nos privamos de enxergar com maior clareza o âmbito em que a ação das mulheres - de diversos grupos de mulheres - era requerida, institucionalizada e muitas vezes temida. Pois não havia ato político-institucional do cidadão que não se confrontasse com forças sobre-humanas muito concretas, muito presentes (e isso independentemente dos nossos pressupostos a respeito). Lidar com essas forças era tarefa que cabia frequentemente ao gênero feminino (Brulé, 1987; Hunter, 1989; Vernant, 1990; Vernant, 1992; Detienne; Sissa, 1990; Keuls, 1993; Sourvinou-Inwood, 1995a; Stears, 1998; Andrade, 2001; Eidinow, 2016).

Em seu artigo "Male and Female, Public and Private, Ancient and Modern”, C. Sourvinou-Inwood (1995a) observa que era propriamente na dimensão pública das práticas religiosas e cívicas que as mulheres (cidadãs) agiam como indivíduos independentes, precisamente porque na ação religiosa a mulher se expunha: aparecia em público, agia e falava por sua própria conta, sem a necessidade de um kúrios responsável, e era chamada pelo nome. Na dimensão privada do oikos, as mulheres estariam submetidas aos poderes masculinos de pais, maridos, irmãos e filhos, além de sofrerem a pressão de um ideal de desaparição: sem nome, sem voz, sem ação, como na oração fúnebre de Péricles. Os epitáfios em honra das mulheres representavam, assim, uma interessante fronteira: eram da ordem do privado, no sentido de que diziam respeito à morte de um membro da família, aos ritos funerários, ao prestígio e aos direitos de um oikos.

Contudo, procurei demonstrar nas pesquisas que realizo sobre a comemoração de mulheres em epigramas funerários (por exemplo, Andrade, 2011) que o artefato produzido para o contexto doméstico das práticas funerárias concedia às mulheres comemoradas por eles um estatuto de honra e visibilidade fora do comum. Isso porque grande parte dos tópicos do discurso das estelas do final do período clássico liga às mulheres virtudes que, na prática corrente da retórica poética, se aplicariam aos homens. ${ }^{5}$ Essa visibilidade não produzia efeitos apenas sobre a comemoração da pessoa que morreu no seio da família, mas remetia a um horizonte certamente tático de requisições femininas.

Eis um exemplo. Por volta de 438 a.C., quando apresentou no teatro de Dioniso em Atenas a tragédia Alceste, Eurípides colocou diante de seus espectadores a figura da rainha Alceste, uma mulher agonizante. As histórias contadas pelos gregos diziam que ela, a esposa de Admeto, fora o único ser 
humano ligado ao rei a aceitar morrer em lugar dele. Admeto chorava a morte de Alceste copiosamente. O coro cantava incessantemente a nobreza da esposa do rei - a melhor dentre todas as mulheres, tal como se repetia diversas vezes - e assegurava aos espectadores que a morte de Alceste lhe traria a glória imorredoura e o renome público. Em meio à dor do esposo e aos elogios do coro, Alceste revela a Admeto o seu desejo final:

Alceste - Vedes, Admeto, em que estado me encontro. Antes de morrer quero que saibas o que desejo. Eu te respeitei a ponto de dar a minha própria vida para resguardá-lo à luz do dia. Morro, quando poderia ter sobrevivido a ti e me unido ao homem tessálio de minha escolha, vivendo nesta casa opulenta e soberana. Mas separada de ti recusei viver com meus filhos órfãos, e desprezei a felicidade que tinha de ser jovem e estar viva. [...] Bem, então, lembre-se de mostrar sua gratidão por isso. Não pedirei um dom equivalente em retribuição pois nada é mais precioso que a vida, mas solicito o que é justo, como verás. Pois tu amas nossos filhos tanto quanto eu, se tens bom juízo. Cuide então para que em minha casa eles permaneçam os mestres e não tome outra mulher que seria para eles madrasta, menos nobre que eu e que, com inveja, se voltaria contra nossos filhos. (Eurípides, Alceste, v. 280-309). ${ }^{6}$

Admeto precisava amar seus filhos prometendo, em vista dessa requisição, não se casar novamente. Esse desejo expresso por Alceste não tinha nenhuma relação com derradeira crise de ciúmes, nem com os caprichos de uma mulher que se ressentia e ativava um débito. Protagonista na peça, a rainha aparecia na cena como mulher publicamente honrada e reconhecida, invertendo os papéis masculino e feminino perante o fenômeno social da morte; numa condição favorável, portanto, aos olhos da comunidade, para fazer valer o juramento de Admeto. Uma promessa de que seus filhos não perderiam o lugar na casa do rei, feita à rainha em seu leito de morte, ratificada pela opinião pública favorável à mulher prudente e virtuosa, eis aqui palavras que, aparentemente, não deveriam ser ditas em vão.

Nenhum desses versos foi recitado no teatro por mulheres. Nenhum deles foi escrito por mulheres, ao menos em acordo com aquilo de que temos conhecimento. E, contudo, nesse espaço de exploração de questionamentos religiosos, políticos e jurídicos que podia ser o teatro grego antigo (Vernant; Vidal-Naquet, 1988; Sourvinou-Inwood, 2003), parece ter sido possível produzir essa espécie de heterotopia (Foucault, 2009, p. 20-36) em que o ordenamento jurídico, político e institucional de uma pólis masculina e cidadã abria 
passagem a requisições fora das instituições jurídicas e atentas ao direito consuetudinário (Gernet, 1988; Vernant, 1992). Esses lugares de requisições informais concediam a palavra e abriam passagem a personagens às quais o estabelecimento da ordem legal da pólis delimitou e ao mesmo tempo limitou acesso à esfera pública do direito - mulheres, escravos quando considerados independentemente da casa (oikos) ao qual pertenciam. ${ }^{7}$ Peculiar e curioso é que justamente nesse momento as personagens femininas se tornem tão esmagadoramente centrais nas peças do teatro trágico; e que venham ao final do V século e por todo o IV século a.C. ganhando uma proeminência que não tinham em períodos anteriores nos elogios funerários privados. Penso que esses fenômenos - estabelecimento institucional da pólis e valorização política, pública, das figuras femininas - estão interligados. E penso que a importância dos atos jurídicos informais no campo social fornece uma das explicações possíveis para essa valorização que acompanha a real exclusão das mulheres da participação direta nas esferas institucionais do governo da pólis. Quando organizamos e observamos juntos esses exemplos fragmentados que temos em tragédias, comédias e espaços funerários, percebemos que é possível e legítimo para uma história social de grupos subalternos ou excluídos trazer à tona uma discussão pública sobre a legitimidade e ao mesmo tempo a fragilidade das requisições feitas aquém da ordem institucional dos tribunais por vozes femininas, diante da pólis como comunidade e Estado.

Retornemos ao campo daquilo que os atenienses chamavam "os costumes" - ta nomizomena, pois a esse campo se ligam quase totalmente a religiosidade, os ritos, especialmente os funerários. São muitas as peças que explicitam o predomínio feminino nas questões referentes aos costumes e seu conflito aberto com as leis da cidade. Em Antígona, por exemplo, a filha de Édipo ignora o decreto do tirano Creonte contra o sepultamento de seu irmão Polinices e perfaz os ritos funerários. O noivo da moça pondera junto ao tirano, que é seu pai: ele não deve puni-la, diz o rapaz, posto que já se faziam ouvir os rumores contra as atitudes do rei em relação aos atos da jovem, reconhecidos como justos diante dos costumes das famílias e da ação correta com relação aos deuses. ${ }^{8}$ Não se trata, aqui, de colocar o público diante do privado, tal não é a força de Antígona; trata-se, antes, de explorar os problemas sérios causados ao poder político e pelo poder político quando se ignoram os costumes que de algum modo vigem na comunidade. Antígona é oficiante nessa dimensão dos nomizomena, e não está ali na tragédia, em primeiro lugar, representando o oikos (embora atue em respeito aos ritos funerários devidos a um irmão). Os atos e palavras de Antígona são amparados por uma comunidade que se 
identifica com a pólis, mas que de modo algum pode ser a priori equiparada ao grupo restrito dos cidadãos. Fica claro, de fato, que o âmbito da cidadania é centralizado na figura de Creonte, mesmo porque os rumores ouvidos pelo filho do rei são rumores das ruas, não das assembleias restritas aos cidadãos. Fica claro, também, que o embate entre Creonte/instituições e Antígona/tradições é propositalmente representado no teatro por um agon entre o "feminino" e o "masculino" (por exemplo: v. 44-100, 450-530; ver Griffith, 2001). A validade da requisição de Antígona para enterrar seu irmão é, no limite, sancionada não por Creonte (lado viril ativo das decisões da pólis), mas pelos "rumores" (dimensão passiva daqueles que Antígona revela como temerosos do poder do tirano), quer dizer, pelo apelo da opinião pública, cuja palavra "fraca", na tragédia, é desdobrada pelo noivo enamorado de Antígona, Hemon.

\section{O logos gunaikos}

O espaço público de exposição feminina na cidade ganha seus contornos de efetividade política: como lugar de importantes requisições públicas porque um dos espaços mais comunitários da cidade antiga, reunindo, para além dos cidadãos, diversos outros grupos em uma mistura que não costumamos levar em consideração ao tratar da pólis como comunidade de cidadãos e "clube de homens". Que relação é essa que, para além da conexão privilegiada do cidadão com sua cidade, faz das mulheres em uma pólis agentes em espaços públicos abertos a uma comunidade mais ampla, comunidade que dialoga com a pólis "Estado" mas vai além dela, em certos momentos concorrendo com ela?

Em 2009, publiquei um artigo sobre o logos gunaikos, a consideração da palavra feminina como palavra vã, fraca e sem credibilidade (Andrade, 2009). Tratava-se do esboço de um estudo que foi aprofundado nos últimos anos e me levou a retornar ao teatro trágico e cômico dos gregos. A problemática pode ser caracterizada pelas palavras finais de Clitemnestra em Agamenon, de Ésquilo:

Não, ó mais querido dos homens, de forma alguma pratiquemos outros males. Pois até isto é muito a colher, mísera safra. É demais a dor, não ensanguentemos. Ide, anciãos, a vossas casas: não sofrais por vossos feitos, era devido o que fizemos. Bastassem-nos estas dores, suportaríamos, míseros feridos por grave garra de Nume. Eis o que afirma a palavra de mulher, se é que o valha considerar. (Ésquilo, Agamenon, v. 1654-1661) ${ }^{9}$ 
Clitemnestra desqualifica o que diz, mas a peça inteira se articula sobre a potência feminina de enganar dizendo a verdade. Assim, é Clitemnestra quem anuncia aos argivos o fim da guerra de Troia; mas como ela sabe? Terá recebido mensagens de sonhos? O coro de cidadãos manifesta descrença. Clitemnestra recebeu sinais de fogo? Mais descrença. É preciso esperar a chegada do mensageiro para que os argivos aceitem a notícia, enquanto em suas palavras tanto Clitemnestra quanto Cassandra já revelam tudo o que está por vir. Mas os cidadãos estão preocupados em estabelecer os fatos, descrentes das palavras das duas mulheres que, no entanto, diziam a verdade, os fatos e suas consequências. Em diversos estudos sobre as representações do feminino e a divisão política, Nicole Loraux nos apresenta o feminino como impotente segundo os avatares do "natural feminino", adunaton, presente nos discursos de historiadores e filósofos (ver Loraux, 1985, p. 7-39; Loraux, 1989; Papadopoulou-Belmehdi, 2005; como contraponto, ver Dewald, 1981). Para a historiadora, essa fraqueza e incapacidade de ação seriam a visão mais próxima da subordinação feminina na sociedade políade (e na sociedade europeia ocidental), dada a concretude da dominação e o valor tanto da virilidade como da divisão masculino-feminino presente nos textos de onde seria possível depreender somente o ponto de vista do dominador. Diferentemente, penso que a posição masculina dominante deve ser avaliada, na medida do possível, segundo o princípio jurídico do contraditório, no confronto dos argumentos dispostos sobre o pano de fundo de um contexto social e não dos textos e das ideias (e representações). Assim, a insistência do veredito de historiadores e filósofos sobre a ausência de força, franqueza e credibilidade do logos das mulheres passaria de determinante (para a nossa compreensão do contexto) a intrigante, já que em arenas de discussão e interação mais amplas como o teatro e os espaços funerários - espaços abertos à interação e circulação de habitantes em geral em contraposição aos espaços privados dos círculos intelectuais - há usos da palavra feminina que contradizem justamente a impotência do "natural feminino”. A palavra feminina está ligada a requisições sociais de justiça, ao estabelecimento "alternativo" da verdade e suas consequências, ao elogio que se contrapõe à tradição poética de censura etc.

A percepção de que não se podem utilizar fontes textuais para analisar ações e ideias ligadas ao universo feminino numa pólis como a ateniense sem alguma cautela, na medida em que a produção escrita seria de autoria masculina, não se sustenta. ${ }^{10}$ Se não bastasse o argumento duvidoso que torna um discurso socialmente produzido incapaz de dizer e fazer mais do que permitiriam os pressupostos genderificados de um autor (e ainda assim teríamos de 
compreender, antes, como se produzem diferenças - e se elas efetivamente se produzem - moduladas pelo sexo dos indivíduos, sendo tanto "indivíduos" quanto "sexo" noções também histórica e antropologicamente variantes, como nos mostram Flax, 1992; Scott, 1999; Laqueur, 2001; Strathern, 2006 e outros), ainda poderíamos recordar que muitas mulheres não apenas influenciavam como podiam ser elas mesmas autoras apócrifas de alguns textos. Um canto coral como o que transcrevo a seguir, retirado de Medeia, dificilmente pode representar apenas uma visão "falocêntrica" de Eurípides:

Coro - ESTROFE: De sacros rios retornam as águas / e Justiça ainda traz tudo de volta. / Entre homens há tramas dolosas, / a confiança dos deuses não vige mais. / As Famas tornarão gloriosa a minha vida, / honra vem ao génos feminino, / não mais dissona fama será das mulheres. /

ANTIESTROFE: As Musas de antigos cantores calarão / os hinos do meu descrédito. / Entre os nossos pendores, / Apolo, guia de ritmos, não pôs / divina canção de lira, a contra ecoar o hino / do génos masculino. A longa vida pode / dizer muito do nosso quinhão e do masculino [...]. (Medeia, v 410-445, em Eurípides, 1995)

Parece-me claro que esse trecho do canto coral de Medeia subentende uma tradição poética de censura ao feminino, na figura da "raça das mulheres", desde Hesíodo, passando por Semônides e presente em tragédias e comédias do período clássico (Andrade, 2001). Ora, essa tradição é, justamente, domínio público: todos conhecem. O argumento de Eurípides é muito plausível nesse contexto: as mulheres coríntias do coro de Medeia vão "contra ecoar", ao mesmo tempo refrear e atacar, o canto masculino que não se cansa de falar mal da "tribo" das mulheres. Não depende, portanto, das posições pessoais do autor, mas do investimento dele, de seu interesse em discutir, na peça, justamente o que nós chamaríamos (não eles) de dominação masculina: o casamento, as incapacidades femininas nessa relação, o destino dos filhos em caso de abandono, a solidariedade entre as mulheres etc. Discussão esta que se desdobra em uma argumentação "simpática" às mulheres, ao sofrimento atribuído claramente no monólogo de Medeia à condição feminina (v. 214-216); como não destacar, nesse caso, a possibilidade de que o autor da peça estivesse capturando rumores bem plausíveis, reconhecidos, ruídos de reclamações ouvidas das mulheres, de certas mulheres, de uma delas, tanto faz? No espaço do teatro, tendo como foco a dimensão de requisições sociais de justiça que dá vida e verossimilhança aos argumentos 
de Medeia para conseguir a solidariedade feminina no silêncio sobre sua vingança, ${ }^{11}$ Eurípides parece ter optado por conferir voz e publicidade à insatisfação de uma, três, um grupo de ou muitas mulheres para com uma tradição poética de louvor heroico e censura (feminina).

É preciso qualificar esse tipo de discurso, colocando-o sob a rubrica das requisições femininas à sociedade políade. Não podemos afirmar que Eurípides defende o "contra ecoar" do canto feminino à palavra masculina; ao contrário, por ser uma tragédia em que a protagonista mata os filhos e escapa em apoteose, a referência explícita de Eurípides a uma tradição poética de censura parece compor o quadro do conflito que termina mal e não propriamente o reconhecimento de uma reivindicação. Contudo, a mesma referência nos permite perceber que o autor está consciente da validade da palavra pública feminina como um dos pontos centrais da disputa que dividia homens cidadãos e mulheres.

Por isso devemos prestar muita atenção aos epitáfios cujo estudo já mencionei, dedicações funerárias elogiosas que passam a ser escritas para mulheres no final do V século e ao longo do IV século a.C. Neles destaca-se uma relação entre os espaços funerários, a operação de exposição/visualização em espaços públicos, o uso dos elogios às mulheres - particularmente a fórmula lírica da "virtude e prudência" - e a possibilidade de se criar uma espécie de "enclave" onde pretensos direitos pudessem ser reclamados pelas mulheres:

- Estela. Ática, primeiro quartel do século IV a.C.

Pâsi thaneîn heímartai, ósoizôosin sù dèpenthosoichtrònécheinélipes, Pausimáchê, progónois mêtro te Phainoppêi kaì patrì Pausanoai sês d'Aretês mnêneîon horân tóde toîs pariôsin swphrosúnês te.

Morrer é o destino de todos os que vivem. Tu, Pausímaca, deixaste um grande sofrimento a teus pais, a tua mãe Fenipe e a teu pai Pausanias. Este memorial é monumento de tua virtude e prudência para todos os que passem ao seu lado e o contemplem. (Peek, 1988, pl. 1654, tradução minha)

- Coluna funerária. Pireu, aprox. 360 a.C.:

Glukéra Thoukleídou ho spásis estì gunaikí, esthlèen kai sóophrona phûnai tèen autèen dokímws toud'étuchen Glukéra.

Glícera, filha de Tuclides. O que é raro na mulher, ser excelente e ao mesmo tempo sensata, é o que alcançou Glícera. (Peek, 1988, pl. 890, tradução minha)

É claro que essas fórmulas elogiosas não são as únicas, mas o seu aparecimento vinculado a mulheres suscita curiosidade, já que a temática da virtude 
e prudência não apenas estava presente nos epitáfios masculinos do século VI a.C. mas ainda tem sua origem na poesia lírica, no elogio ao guerreiro (Burton, 2003; Tsagalis, 2008; Andrade, 2011). Mais curioso ainda, portanto, quando nos colocamos agora não mais num universo restrito a famílias aristocráticas que prestam contas da morte prematura das filhas, mas num discurso altamente cívico e viril que passa a ser utilizado na comemoração funerária de virtudes femininas, aquelas mesmas que se utilizava para os homens e os guerreiros na poesia lírica. Como se as mulheres merecessem, agora, aqueles louvores que a poesia reservava aos da "raça masculina".

Nem todas as dedicações femininas e nem todas as masculinas utilizam a fórmula da "virtude e prudência" e, portanto, os exemplos que analiso aqui foram escolhidos propositalmente. Mas a questão não é a de que todas as mulheres recebam os mesmos elogios; trata-se, outrossim, de compreender por que esses elogios se tornam disponíveis para as mulheres, mesmo que sejam algumas. A meu ver, esses fenômenos estão interligados e relacionam-se diretamente ao contexto político e ao fortalecimento das instituições democráticas atenienses. Discordo de Osborne (1997), que sugere uma conexão entre a presença dos elogios femininos e a melhora no status das mulheres cidadãs por conta da lei de cidadania de Péricles (461 a.C.), incluindo nos requisitos para ser considerado cidadão a filiação a "mãe ateniense". A meu ver, a questão não se resolve pela "melhora do status", como defende Osborne, e sim, mais diretamente, pela abertura de margens de manobra para as mulheres da cidade não simplesmente as "cidadãs" - diante das instituições da pólis. Ao que parece, o espaço das mulheres numa comunidade que é política além de ser institucional ("de cidadãos") modifica-se ou ganha contornos de visibilidade entre o final do arcaico e o período clássico.

Os elogios funerários implicam um uso heterotópico do espaço público pelas mulheres que merece tornar-se tema e problema para a história (política) da pólis. E por que heterotópico? Por deslocar, por exemplo, uma apropriação predominantemente discursiva do espaço da pólis, entre o "público" (koinos) e o "privado" (idios), para outra divisão, entre "interior" e "exterior", repolitizando nesse movimento a visibilidade, a exposição pública (Andrade, 2005; Andrade, 2011). Ainda: por desviar dos espaços institucionais construídos para tal o debate político em torno dos direitos e do estatuto dos indivíduos e de suas famílias diante da comunidade de cidadãos e reconduzi-lo à perspectiva de uma comunidade mais vasta que convive no teatro, nos santuários, na ágora, nas necrópoles etc. Enfim, por trazer para esses outros espaços efetivos a questão da vida comum (Andrade, 2002), da produção mesma da comunidade. 
Vemos uma situação parecida nos estudos de Nadia Seremetakis sobre os cantos antifônicos das mulheres carpideiras em funerais nas aldeias do sul da Grécia (Seremetakis, 1993). A antropóloga frisa que a prática dos cantos funerários pelas mulheres de aldeia entra em choque tanto com os inquéritos jurídicos oficiais quanto com as imposições contrárias à tradição das carpideiras por parte da Igreja ortodoxa e do Estado nacional grego:

As performances de lamentação dos maniatas ligam-se à significação pessoal e à validação social (interpessoal) do pónos (penas, dor). O conceito maniata de dor integra condições físicas e emocionais, referências coletivas e individuais, discursos de lamentação e "juramentais". A dor é crucial para as estratégias de requisição do verdadeiro das mulheres maniatas, quando em conflito com vários aspectos da estrutura social. É considerada indispensável à legitimação do discurso em performances de lamentação. Como as mulheres costuram os diversos elementos da performance de lamento - dor, biografia, identidade de gênero e requisições do verdadeiro - em um único ritual é a tarefa descritiva deste paper. (Seremetakis, 1993, p. 122)

A antropóloga não utiliza a noção de heterotopia para a análise do ritual do cântico fúnebre das maniatas, mas explora em seu trabalho as relações tensas e por vezes de oposição entre passado e presente, rural e urbano, Estado, Igreja e comunidade, sugerindo que, por meio do rito feminino, um padrão de resistência política se eleva contrariando os avanços da "modernidade" sobre o regime de verdade dos cantos fúnebres. A performance gera uma abertura espaço-temporal para um "dizer a verdade" que depende da realização do cântico: verdade sobre a vida do morto, sobre as condições de sua morte, sobre o tipo de relacionamentos que se quebram com sua partida etc. Desconsideradas pelas instituições jurídico-políticas positivas do Estado nacional grego, as mulheres de aldeia e seus cantos nem por isso falam menos uma verdade da comunidade.

CONSIDERAÇões FINAIS: A PALAVRA DE MULHER E O ESPAÇO DA PÓLIS Nenhum homem é uma ilha, nenhuma ilha é uma ilha. (Ginzburg, 2004, p. 113)

Nenhuma ilha é uma ilha. Longe de reforçar o relativismo, a frase de Ginzburg remete a uma ideia bem mais simples de abertura e possibilidade: vamos investir no diálogo e nas dinâmicas sociais ou nos modelos e visões de 
mundo? Vamos optar pela abertura e possibilidade, ou vamos consolidar nosso isolamento insular?

O que significa buscar a voz e a agência das mulheres num manancial de "história antiga" pouco afeito a essa voz e agência e tão construído em sua tradição clássica com modelos, sistemas, campos e autoridades milenares? De fato, se concordássemos com Nicole Loraux quanto à (ambígua) impossibilidade de se fazer uma história das mulheres no período clássico grego (Loraux, 1988, p. 103-124), teríamos de concordar também em que o próprio discurso historiográfico dos antigos exclui da representação da agência das mulheres sua potência, quer dizer, sua atividade, mas ainda sua racionalidade ou utilidade política. Contudo, justamente porque a "representação" é um construto no âmbito do diálogo entre o historiador e a sociedade que busca estudar - uma ilha -, é preciso estranhar-se com ela, quebrá-la em alguns pedaços e perguntar-se por que, por exemplo, intelectuais na Atenas clássica que falavam sobre justiça e política importavam-se tanto com as devidas distinções entre uma virilidade ativa e uma feminilidade passiva; e ainda como esses intelectuais - filósofos, historiadores, retóricos, tragediógrafos, comediógrafos - passavam do masculino/feminino ao homem/mulher, marido/esposa, visando práticas concretas, visando intervir na vida social em sua época. Um formigueiro.

Intervir. Talvez a maior ambição dessa problemática geral da "voz das mulheres" seja justamente ter êxito em refletir e escrever sobre agentes, práticas, ideias "sem história" - ou deveríamos dizer, com outras histórias possíveis 12 $^{12} \mathrm{~A}$ escuta atenta às atribuições de vozes, condutas, opiniões, requisições às mulheres no campo social, mesmo que não possa ser individualizada e atribuída a esta(s) ou aquela(s) mulher(es) "de verdade", é postura sine qua non; e arriscada, porque poder e governo são passos que nunca foram viáveis às mulheres atenienses, como ensinam os manuais de história antiga; ${ }^{13}$ agenciamentos políticos cotidianos, contudo, eis o "ganho" que nunca foi capitalizado, e por isso mesmo vêm permanecendo à margem da historiografia do mundo antigo, justamente pela dificuldade de se trazer à tona uma dimensão de reprodução da vida social para a qual a pluralidade dos meios não institucionais ou táticos de ação é fundamental. Para compreender as práticas de exposição feminina sob um ponto de vista político, precisamos, assim, e no mínimo, levar a sério a construção sólida das instituições da cidade-Estado como modelo e lugar-próprio reivindicado pelos cidadãos de uma político-pólis, em seu diálogo e sua projeção sobre uma comunidade cotidiana ativamente constituinte ou geopolis, ${ }^{14}$ pois é nesse intervalo possível que intervêm as negociações em torno da reprodução da hegemonia do cidadão sobre o espaço habitado. A 
política no cotidiano - ou na "vida comum" (Andrade, 2002) - não diz respeito necessariamente às repetições, ninharias e anonimatos, abordagem cujo propósito de resgatar fatos da vida das mulheres atenienses no passado está longe do sentido que gostaria de ver impresso nas pesquisas sobre uma "cidade das mulheres". Cotidiano é uma dimensão de reprodução em que o poder como potência, exercício e regulamentação circula, promete, faz e desfaz nas "brechas" de uma ideologia política, trazendo à tona (des)caminhos que a polemologia do cotidiano impõe ao que se diz e ao que se faz, e que incide sobre os focos de instabilidade que afloram sempre que uma nova requisição, negociação ou evento gera tensões e contradições no tecido aparentemente unânime do senso comum e do hábito. ${ }^{15}$

Mas é viável uma tal análise atenta à palavra, à visibilidade política do feminino com as fontes textuais (e outras) que conhecemos e de que dispomos para a escrita da história da Atenas clássica? Minha aposta é afirmativa. Espero que os exemplos analisados neste artigo se combinem à curiosidade saudável dos pesquisadores que estudam o Mediterrâneo antigo, na também esperança de que, nas próximas décadas, estejamos de algum modo dedicados a fazer ressoar na historiografia da Antiguidade as "armas dos fracos" como armas de verdade. Um dos desafios, nesse caso, é compreender a produção da vida comum como política constituinte, o trabalho vivo das agências plurais e diversas de seus "habitantes". A "palavra de mulher", o logos gunaikos, seu louvor ou censura, se relaciona com pontos de vista sobre a agência de grupos femininos imaginados reais e tematiza a questão política da pólis como questão constituinte da pólis. Nesse sentido, tenho feito certo esforço para não partir de (nem repousar em) modelos como o da reciprocidade (mulher/troca), da divisão do trabalho (masculino/feminino, produção/reprodução), das relações binárias de gênero, das esferas pública e privada, da dominação masculina, enfim, não necessariamente porque discorde dessas formulações mas, necessariamente, porque, se nenhuma ilha é uma ilha e nenhuma história é finita, é importante dar a palavra em lugar de autenticá-la.

\section{REFERÊNCIAS}

AGAMBEN, Giorgio. Homo Sacer: poder soberano e vida nua. Tradução de Henrique Burigo. 2. ed. Belo Horizonte: Ed. UFMG, 2007.

ANDRADE, Marta Mega de. A cidade das mulheres: cidadania e alteridade feminina na Atenas clássica. Rio de Janeiro: LHIA, 2001. 
ANDRADE, Marta Mega de. O espaço funerário: comemorações privadas e exposição pública das mulheres em Atenas, séculos VI-IV a.C. Revista Brasileira de História, São Paulo: Anpuh, v. 31, n. 61, p. 185-208, 2011.

ANDRADE, Marta Mega de. Gênero, poder e diferenças. Phoînix, Rio de Janeiro: 7 Letras, n. 11, p. 171-187, 2005.

ANDRADE, Marta Mega de. Logos Gunaikos. In: BUSTAMANTE, Regina; LESSA, Fábio (org.). Dialogando com Clio. Rio de Janeiro: Mauad, 2009. p. 111-122.

ANDRADE, Marta Mega de. A vida comum: espaço, cotidiano e cidade na Atenas Clássica. Rio de Janeiro: DP\&A, 2002.

BLOK, Josine. Virtual Voices: Toward a Choreography of Women's Speech in Classical Athens. In: LARDINOIS, Andre; MCCLURE, Laura (ed.). Making Silence Speak. Oxford: Oxford University Press, 2001. p. 95-116.

BRUIT-ZAIDMAN, Louise. Les filles de Pandora: femmes et rituels dans la cité. In: SCHMITT-PANTEL, Pauline (dir.). Histoire des Femmes en Occident I. Paris: Plon, 1991. p. 363-403.

BRULÉ, Pierre. La Fille d'Athènes. Paris: Les Belles Lettres, 1987.

BURTON, Diana. Public Memorials, Private Virtues: Women on Classical Athenian Grave Monuments. Mortality, v. 8, p. 20-35, 2003.

CANTARELLA, Eva. Pandora's Daughters: The Role and Status of Women in Greek and Roman Antiquity. Baltimore, MD: Johns Hopkins University Press, 1987.

CERTEAU, Michel de. A invenção do cotidiano. I. Artes de fazer. 2. ed. Tradução de Ephrain Ferreira Alves. Petrópolis: Vozes, 1994.

COHEN, David. Seclusion, Separation and the Status of Women in Classical Athens. Greece and Rome, v. 36, p. 1-15, 1989.

DETIENNE, Marcel. Os mestres da verdade na Grécia arcaica. Tradução de Andrea Daher. Rio de Janeiro: Zahar, 1988.

DETIENNE, Marcel; SISSA, Giulia. A Força das mulheres: Hera, Atena e congêneres. In: DETIENNE, Marcel; SISSA, Giulia. Os deuses gregos. Tradução de Rosa Maria Boaventura. São Paulo: Companhia das Letras, 1990. p. 245-265.

DEWALD, Carolyn. Women and Culture in Herodotus' Histories. Women's Studies, v. 8 , p. $95-127,1981$.

DILLON, Matthew. Girls and Women in Classical Greek Religion. London: Routledge, 2002.

EIDINOW, Esther. Envy, Poison and Death: Women on Trial in Classical Athens. Oxford: Oxford University Press, 2016.

EURÍPIDES. Medeia. Tradução de José Antonio A. Torrano. São Paulo: Hucitec, 1995. FLAX, Jane. Pós-modernismo e relações de gênero na teoria feminista. In: HOLLANDA, Heloisa B. de. (org.). Pós-modernismo e política. Rio de Janeiro: Rocco, 1992. p. 217-250. 
FOLEY, Helene. The Politics of Tragic Lamentation: Female Acts in Greek Tragedy. Princeton, NJ: Princeton University Press, 2001. p. 19-56.

FOUCAULT, Michel. Le corps utopique, Les hétérotopies. Paris: Lignes, 2009.

FOUCAULT, Michel. Prefácio. In: FOUCAULT, Michel. As palavras e as coisas. 2. ed.

Tradução de Salma Tannus Muchail. São Paulo: Martins Fontes, 1999. p. 9-22.

FOXHALL, Lynn. The Law and the Lady. In: FOXHALL, Lynn; LEWIS, Andrew (ed.). Greek Law and Its Political Setting. Oxford: Oxford University Press, 1996. p. 133-152.

GAGARIN, Michael. Women in Athenian Courts. Dike, v. 1, p. 39-51, 1998.

GAGARIN, Michael. Women's Voices in Attic Oratory. In: LARDINOIS, Andre; MCCLURE, Laura (ed.). Making Silence Speak. Oxford: Oxford University Press, 2001. p. 161-176.

GARLAND, Robert. Religious Authority in Archaic and Classical Athens. The Annual of the British School in Athens, v. 79, p. 75-123, 1984.

GERNET, Louis. Droit et instituitions en Grèce antique. 2eme. éd. Paris: Flammarion, 1988.

GINZBURG, Carlo. Nenhuma ilha é uma ilha. Tradução de Samuel Titan Jr. São Paulo: Companhia das Letras, 2004.

GINZBURG, Carlo. Relações de força: História, retórica, prova. Tradução de Jônatas Batista Neto. São Paulo: Companhia das Letras, 2002.

GOULD, John. Law, Custom and Myth: Aspects of the Social Position of Women in Classical Athens. Journal of Hellenic Studies, v. 100, p. 38-59, 1980.

GREENWOOD, Emily. Reception Studies: The Cultural Mobility of Classics. Daedalus, v. 145, n. 2, p. 41-78, 2016. Disponível em: https://link-gale.ez29.capes.proxy.ufrj. $\mathrm{br} / \mathrm{apps} / \mathrm{doc} / \mathrm{A} 452992979 / \mathrm{AONE} ? \mathrm{u}=$ capes\&sid=AONE\&xid=47b05843. Acesso em: 7 maio 2020.

GRIFFITH, Mark. Antigone and Her Sister(s): Embodying Women in Greek Tragedy. In: LARDINOIS, Andre; MCCLURE, Laura (ed.). Making Silence Speak. Oxford: Oxford University Press, 2001. p. 117-136.

GUARINELLO, Norberto Luis. Uma morfologia da História: as formas da História Antiga. Politeia, Vitória da Conquista, v. 3, p. 41-61, 2003.

HARRIS, Edward. The Flawed Origins of Greek Democracy. In: HAVLÍCEK, Ales et al. (ed.). Nous, polis, nomos. Sankt Augustin: Academia Verlag, 2016. p. 43-55.

HENRIKSÉN, Christer (ed.). A Companion to Ancient Epigram. Medford: John Wiley \& Sons, 2019.

HUNTER, Virginia. Women's Authority in Classical Athens. Echos du monde classique / classical views, v. 33, n. 8, p. 39-48, 1989.

JUST, Roger. Women in Athenian Law and Life. London: Routledge, 1989.

KEULS, Eva. The Reign of the Phallus: Sexual Politics in Ancient Athens. Los Angeles: University of California Press, 1993. 
LAQUEUR, Thomas. Inventando o sexo: corpo e gênero dos gregos a Freud. Tradução de Vera Whately. Rio de Janeiro: Relume-Dumará, 2001.

LARDINOIS, Andre; MCCLURE, Laura (ed.). Making Silence Speak: Women's Voices in Greek Literature and Society. Princeton, NJ: Princeton University Press, 2001.

LORAUX, Nicole. La cité, l'historien, les femmes. Pallas, v. 32, p. 7-39, 1985.

LORAUX, Nicole. Les expériences de Tirèsias: le féminin et l'homme grec. Paris: Gallimard, 1989.

LORAUX, Nicole. Notes sur un impossible sujet de l'histoire. Les cahiers du Grif, n. 37/38, p. 113-124, 1988.

MANSOURI, Saber. L'agora athénienne ou le lieu de travail, des discussions et des nouvelles politiques: chercher la politique là où elle n'est apparemment pas. Dialogues d'histoire ancienne, v. 28, n. 2, p. 41-63, 2002.

MAZON, Paul. Sophocle. Antigone. Paris: Les Belles Lettres, 1955.

MOSSÉ, Claude. Astè kai Politis: la dénomination de la femme athénienne dans les plaidoyers démosthéniennes. Ktéma, v. 10, p. 77-80, 1985.

NEGRI, Antonio. O poder constituinte. Tradução de Adriano Pilatti. Rio de Janeiro: DP\&A, 1999.

OSBORNE, Robin. Law, the Democratic Citizen and the Representation of Women in Classical Athens. Past and Present, v. 155, p. 3-33, 1997.

PAPADOPOULOU-BELMEHDI, Ioanna. Histoire des hommes, histoire des femmes dans l'oeuvre de Nicole Loraux. Espaces Temps, v. 87-88, p. 49-64, 2005.

PATTERSON, Cynthia. The Family in the Greek History. Cambridge, MA: Harvard University Press, 1998.

PEEK, Werner. Griechische Vers-Inschriften. I. Grab-Epigramme. Chicago: Ares Publishers, 1988.

POMEROY, Sarah. Goddesses, Whores, Wives and Slaves. New York: Schocken Books, 1975.

POMEROY, Sarah. Xenophon, Oeconomicus: A Social and Historical Commentary. Oxford: Clarendon Press, 1994.

POWELL, Anton. Citizen Women of Athens. In: POWELL, Anton. Athens and Sparta: Constructing Greek Political and Social History from 478 BC. New York: Routledge, 1988. p. 341-392.

REDFIELD, James. O homem e a vida doméstica. In: VERNANT, Jean-Pierre (org.). O homem grego. Tradução de Maria Jorge V. de Figueiredo. Lisboa: Presença, 1994. p. 147-171.

ROUSSELLE, Aline. Porneia: sexualidade e amor no Mundo Antigo. Tradução de Lygia Araújo Watanabe e Thereza Christina Ferreira Stummer. São Paulo: Brasiliense, 1984.

SCHAPS, David. What Was Free about a Free Athenian Woman. Transactions of American Philological Association, v. 128, p. 161-188, 1998. 
SCHAPS, David. The Women Least Mentioned: Etiquette and Women's Names. Classical Quarterly, v. 27, n. 2, p. 323-330, 1977.

SCHMITT-PANTEL, Pauline. Un fil d'Ariadne. In: SCHMITT-PANTEL, Pauline (org.). Histoire des Femmes en Occident I. Paris: Plon, 1991. p. 21-27.

SCOTT, Joan. Gender and the Politics of History. 2. ed. New York: Columbia University Press, 1999.

SCOTT, Joan. A História das Mulheres. In: BURKE, Peter (org.). A escrita da História. Tradução de Magda Lopes. São Paulo: Ed. Unesp, 1992. p. 63-95.

SEBILLOTE-CUCHET, Violaine. Gender Studies et domination masculine: Les citoyennes de l'Athènes classique, un défi pour l'historien des institutions. Cahiers Glotz, v. 28, p. 7-30, 2017.

SEREMETAKIS, Nadia. Durations of Pain: The Antiphony of Death and Women's Power in Southern Greece. In: SEREMETAKIS, Nadia. Ritual, Power and the Body. New York: Pella Publishing, 1993. p. 119-149.

SOARES, Fabio Morales. A democracia ateniense pelo avesso. São Paulo: Edusp, 2014. SOURVINOU-INWOOD, Christianne. Further Aspects of Polis Religion. A.I.O.N., v. 10, p. 259-274, 1988.

SOURVINOU-INWOOD, Christianne. Male and Female, Public and Private, Ancient and Moder. In: REEDER, Ellen (ed.). Pandora. Princeton, NJ: Princeton University Press, 1995a. p. 111-121.

SOURVINOU-INWOOD, Christianne. Reading Greek Death. Oxford: Clarendon Press, $1995 \mathrm{~b}$.

SOURVINOU-INWOOD, Christianne. Tragedy and Athenian Religion. New York: Lexington Books, 2003.

SOURVINOU-INWOOD, Christianne. What is Polis Religion? In: MURRAY, Oswyn; PRICE, Simon (ed.). The Greek City from Homer to Alexander. Oxford: Oxford University Press, 1990. p. 295-322.

STEARS, Karen. Death Becomes Her: Gender and Athenian Death Ritual. In: LUNDELL, Sue; WILLIAMSON, Margareth (ed.). The Sacred and the Feminine in Ancient Greece. London: Routledge, 1998. p. 113-127.

STEHLE, Eva. The Good Daughter: Mother's Tutelage in Erinna's Distaff and Fourth Century Epitaphs. In: LARDINOIS, Andre; MCCLURE, Laura (ed.). Making Silence Speak. Oxford: Oxford University Press, 2001. p. 179-200.

STRATHERN, Marilyn. O gênero da dádiva: problemas com as mulheres e problemas com a sociedade melanésia. Tradução de André Villalobos. Campinas: Ed. Unicamp, 2006.

TARDE, Gabriel. Os possíveis. In: TARDE, Gabriel. Monadologia e Sociologia - e outros ensaios. Tradução de Paulo Neves. São Paulo: Cosac \& Naify, 2007. p. 193-233.

TSAGALIS, Christos. Inscribing Sorrow: Fourth-century Attic Funerary Epigrams. Berlin: Walter de Gruyter, 2008. 
VATIN, Claude. Citoyens et non-citoyens dans le monde grec. Paris: Société d'Édition d'Enseignement Supérieur, 1984.

VERNANT, Jean-Pierre. O casamento. In: VERNANT, Jean-Pierre. Mito e sociedade na Grécia antiga. Tradução de Myriam Campello. Rio de Janeiro: J. Olímpio Ed., 1992.

VERNANT, Jean-Pierre. "Héstia Hermes". In: VERNANT, Jean-Pierre. Mito e pensamento entre os gregos. Tradução de. Haiganuch Sarian. 2. ${ }^{\mathrm{a}}$ ed. São Paulo: Paz e Terra, 1990., p. 189-242.

VERNANT, Jean-Pierre. As origens do pensamento grego. Tradução de Ísis Borges B. da Fonseca. 2. ed. Rio de Janeiro: Difel, 2002.

VERNANT, Jean-Pierre; VIDAL-NAQUET, Pierre. Mito e Tragédia na Grécia Antiga. Tradução de Anna Lia de Almeida Prado, Maria da Conceição M. Cavalcante e Filomena Yoshie Hirata Garcia. São Paulo: Brasiliense, 1988.

VLASSOPOULOS, Kostas. Free Spaces: Identity, Experience and Democracy in Classical Athens. Classical Quarterly, v. 57, n. 1, p. 33-52, 2007.

\section{NOTAS}

${ }^{1}$ Apenas uma faceta de um tema tão amplo quanto o da recepção dos "clássicos" (ver GREENWOOD, 2016).

2 "As heterotopias inquietam, sem dúvida porque solapam secretamente a linguagem, porque impedem de nomear isto e aquilo, porque fracionam os nomes comuns ou os emaranham, porque arruínam de antemão a "sintaxe", [...] as heterotopias (encontradas tão frequentemente em Borges) dessecam o propósito, estancam as palavras nelas próprias, contestam, desde a raiz, toda possibilidade de gramática; desfazem os mitos e imprimem esterilidade ao lirismo das frases" (ver FOUCAULT, 1999, p. 12).

${ }^{3}$ Os elogios funerários a esposas e filhas ao longo dos V e IV séculos a.C. podem ser compreendidos também dentro desse horizonte de expectativas, o que confere ao casamento, do ponto de vista feminino, um papel estratégico na vida social, tão importante quanto a fraqueza de suas possibilidades institucionais de reivindicação alça ao primeiro plano direitos e prerrogativas tradicionais de status. Acredito que este seja um primeiro caminho para se compreender, por exemplo, a importância de certos espaços livres (VLASSOPOULOS, 2007) para o desdobramento de requisições femininas aquém do direito políade.

${ }^{4}$ Muito se refletiu sobre a "pólis religiosa" (por exemplo e como ref. ver Sourvinou-Inwood, 1988; Sourvinou-Inwood, 1990). Porém, quando religião e política se associam nas análises, geralmente o viés das relações institucionais concentra o foco do problema (GARLAND, 1984; VATIN, 1984; POWELL, 1988; COHEN, 1989; BRUIT-ZAIDMAN, 1991; DILLON, 2002). Ainda é preciso compreender a dimensão política das práticas religiosas femininas (tidas comumente como "cívicas", mas não "políticas"), como sugerem explicitamente Sourvinou-Inwood, 1995a e indiretamente Redfield, 1994. 
${ }^{5}$ Além da fórmula poética arcaica arete kai sophrosune (BURTON, 2003; TSAGALIS, 2008), outros atributos como chreste, sophron, agathe, eusunetos, eusebes (SOURVINOU-INWOOD, 1995b, p. 117-120) passam a ser utilizados para homens e mulheres. Ver os diversos estudos organizados por Henriksén, 2019.

${ }^{6}$ Disponível em: http://www.perseus.tufts.edu/hopper/text?doc=Perseus\%3Atext\%3A199 9.01.0087\%3Acard\%3D280. Acesso em: 21 jan. 2020, tradução minha.

${ }^{7}$ Sobre a questão da relação das mulheres atenienses com os tribunais do ponto de vista institucional e jurídico, ver Schaps, 1977; Schaps, 1998; Mossé, 1985; Gould, 1980; Patterson, 1998; Just, 1989. Sobre a relação das mulheres com os tribunais sob um viés sociológico, ver Cohen, 1989; Sourvinou-Inwood,1995a; Foxhall, 1996; Blok, 2001; Gagarin, 1998; Gagarin, 2001; Eidinow, 2016. Sobre as possibilidades de requisições femininas fora dos espaços institucionais da cidadania e particularmente em contextos funerários, ver Sourvinou-Inwood, 1995a; Stears, 1998; Blok, 2001; Foley, 2001; Stehle, 2001; Andrade, 2009.

8 "Hemom: [...] Posso ouvir na sombra os cidadãos, e escuto Tebas gemer sobre a sorte dessa moça. 'Entre todas as mulheres ela é sem dúvida aquela que menos merece perecer na ignomínia por atos que fazem a glória! Ela não quis deixar que um irmão morto em combate desaparecesse sem sepultura, vítima de pássaros e de cães vorazes: não é ela digna das honras mais evidentes?' Eis aí o rumor obscuro que sem ruído cresce contra ti." (Sófocles, Antígona, v. 690-700, revisado por mim a partir da tradução de Mazon, 1955).

${ }^{9}$ Tradução minha a partir de:

http://www.perseus.tufts.edu/hopper/text?doc=Perseus\%3Atext\%3A1999.01.0003\%3Acar d\%3D1649. Acesso em: 13 dez. 2019.

${ }^{10}$ Debates levados a cabo por Pomeroy, 1975; Rousselle, 1984; Cantarella, 1987; Schmitt-Pantel, 1991 por exemplo, ao longo das décadas de 1970 e 1980, atualmente reinseridos numa perspectiva de recuperação da palavra feminina como na coletânea dirigida por Lardinois; McClure, 2001.

${ }^{11}$ Por exemplo, no que se refere ao "juramento do leito" ao qual Medeia confere muita importância, e que é desdenhado por Jasão e por Creonte como se se tratasse de uma prática sem valor porque não vinculada ao estado de direito representado pelo rei Creonte. Ver v. 265 / 292-323 e os debates agônicos entre Medeia e Creonte (v. 400-409), e Medeia e Jasão (v. 446-521 e 1323-1388) (EURÍPIDES, 1995). Ver ainda Andrade, 2009.

12 "A inteligência dos fatos exige o conhecimento dos possíveis". Penso imediatamente em Tarde (2007, p. 200).

${ }^{13}$ Para uma visão crítica muito importante desse ponto de vista que valoriza a cidadania em acordo com nossos moldes institucionais, ver Sebillote-Cuchet, 2017, p. 7-30.

${ }^{14}$ Constituinte no sentido que lhe confere Negri (1999, p. 7-56), mas também em profunda empatia com a discussão de Agamben, na introdução do Homo Sacer (AGAMBEN, 2007, p. 9-22).

${ }^{15}$ Michel de Certeau menciona a necessidade de se adotar uma "visão polemológica da 
cultura" (CERTEAU, 1994, p. 44), a fim de ressaltar que a cultura "se desenvolve no elemento de tensões, e muitas vezes de violências, a quem fornece equilíbrios simbólicos, contratos de compatibilidade e compromissos mais ou menos temporários" (p. 44-45). A polemologia do cotidiano, a meu ver, é o corolário dessa visão polemológica da cultura, que deseja fazer emergir justamente as tensões e negociações ou simplesmente as táticas que, no cotidiano, perfazem o contorno da repetição ou da mudança possíveis.

Artigo recebido em 24 de janeiro de 2020.

Aprovado em 25 de maio de 2020. 